\title{
A Study on Contraceptive Action
}

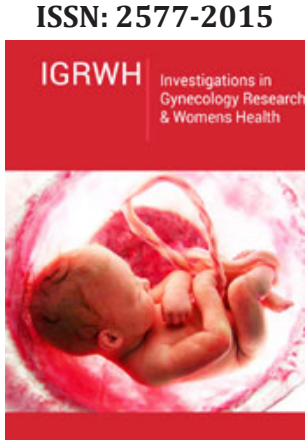

*Corresponding author: Nripendra S, Department of Pharmacy, VBS Purvanchal University, Jaunpur, India

Submission: 監June 03, 2019

Published: 豋June 12, 2019

Volume 2 - Issue 5

How to cite this article: Nripendra S, RituS, Surendra S, Puja. A Study on Contraceptive Action. Invest Gynecol Res Women's Health.2(5). IGRWH.000550.2019. DOI: 10.31031/IGRWH.2019.02.000550

Copyright@ Nripendra S, This article is distributed under the terms of the Creative Commons Attribution 4.0 International License, which permits unrestricted use and redistribution provided that the original author and source are credited.

\author{
Nripendra $S^{1 *}$, Ritu $S^{2}$, Surendra $S^{1}$ and Puja ${ }^{1}$ \\ ${ }^{1}$ Department of Pharmacy, VBS Purvanchal University, Jaunpur, India \\ ${ }^{2}$ Department of Pharmaceutics, RRS college of Pharmacy, Amethi, India
}

\begin{abstract}
Vaginal contraceptive products have been available for many years and usually contain the membrane surfactant nonoxynol-9 (N-9) as one of the main ingredients. However, the major drawback of using surfactants is their detergent-type cytotoxic effect on vaginal cells. Besides, $\mathrm{N}-9$ is also known to inactivate lactobacilli leading to disturbance of the vaginal microflora, which in turn increase the chances of STI/HIV transmission. Neem seed oil proved to be spermicidal against rhesus monkey and human spermatozoa in-vitro. Hexane extract of neem seed was reported to be precursor for immune contraceptive guided fraction whereas lyophilized neem leaf extract which is hydrophilic in nature has shown spermicidal activity against human spermatozoa in vitro. This review article proposes hydrophilic lipid for the extraction of hydrophilic and hydrophobic constituents from neem leaf to give novel aqueous neem leaf extract (NANE) which involves no use of organic solvent or thermal application and have no side effects. It is interesting to note that use of herbal contraceptives generally did not lead to permanent sterility, since discontinuation of the treatment allowed a prompt return to normal fertility.
\end{abstract}

Keywords: Contraception; Spermicidal activity; Novel aqueous neem leaf extract (NANE)

\section{Introduction}

The population explosion is a global problem that poses significant threat to the quality of life, more particularly in the underdeveloped and developing countries [1]. The extraordinary growth of the world population stands as one of the significant events of the modern era to think over. The current world population is around 6.46 billion and that of India is around 1.1 billion. The United Nations 'medium' projection has predicted that world population, which crossed the five billion mark in 1987, will increase to 10 billion by the year 2050 [2]. One of the critical problems of the developing countries like India is its geometrical increase in human population. Today we understand that our sheer numbers have increased so much that they are straining Earth's capacity to supply food, energy and raw materials. Advances in medicine and public health have led to a significant decrease in mortality and an increased life expectancy. This population explosion will have negative impact on our economic policies and would simultaneously misbalance our socio-economic infrastructure. Thus, the control of human fertility in the sense of its limitation is the most important and urgent of all-biosocial and medical problem confronting mankind today [3].

Approximately 49 percent of pregnancies in the United States are unintended. One cost analysis found that compared with pregnancy and abortion, contraception saves an estimated $\$ 9,000$ to $\$ 14,000$ per woman of childbearing age over a five-year period. Although Male or female condoms used correctly and consistently is the only available method shown to be effective in preventing both unwanted pregnancies and ST/HIV infections, women often have little power to negotiate the use of condoms with their partners and are unable to protect themselves from nonconsensual coercive sex. Further Female condoms are expensive and are not readily available in developing countries. Contraception is literally the prevention of conception, but generally is taken to mean the prevention of pregnancy [4]. Further, Overpopulation, particularly in developing countries, is complicated by the pandemic of sexually transmitted infections (STI) and human immunodeficiency virus (HIV) infections. The high incidence of these infections is owing to heterosexual intercourse, and the infections spread more readily from men to women than from women to men [4] New HIV infections 
have been reduced by $47 \%$ since the peak in 1996. In 2017, there were 1.8 million [1.4 million-2.4 million] new HIV infections, compared to 3.4 million [2.6 million-4.4 million] in 1996 (UNAIDS, 2017). The first cases of HIV infection and AIDS in India were detected in 1986. HIV infections have been reported in all the states and union territories in India and, with a population of 1 billion, and half of the population between 15 and 49 years of age, the HIV epidemic has resulted in a significant public health burden. India is facing one of the largest burdens of HIV infection, and heterosexual transmission is the commonest route of HIV transmission. More than one third (35\%) of women around the world have experienced

\section{Methods of Contraception}

\section{Hormonal control of fertility}

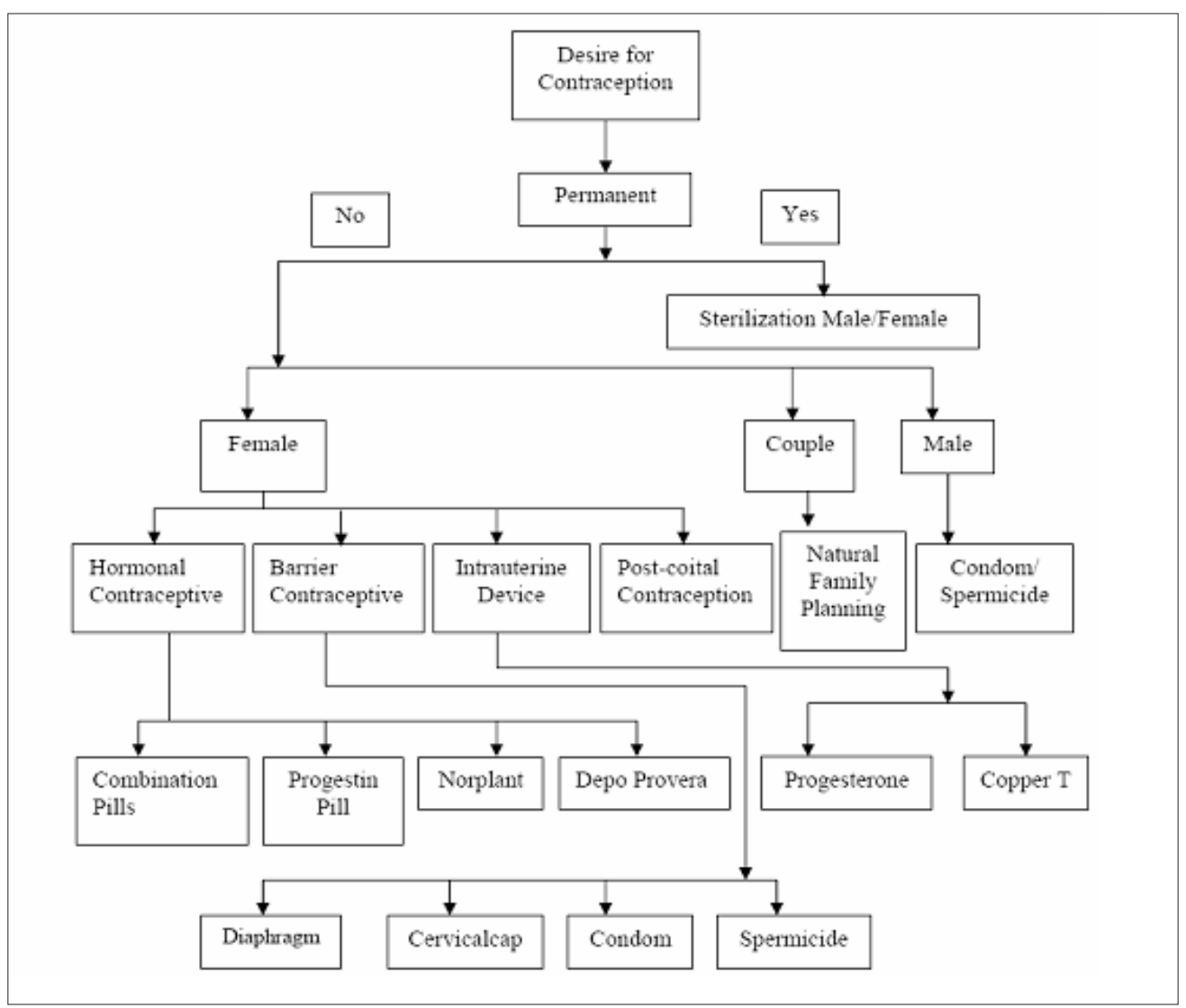

Figure 1: Various methods of contraception.

The most effective method of contraception, the birth control pill, is based on oral administration of steroids. Estrogens and progestin are used either combined or, as with the "minipill", progestin is used alone (Figure 1). In addition, various combinations of steroids can also be administered as long-acting injectable preparations or via intrauterine systems. The pills to be effective via the oral route, estradiol and progesterone cannot be used since they are metabolized in the gastrointestinal tract and liver. As a consequence, synthetic estrogens such as mestranol (50-100 $\mu \mathrm{g} /$ day) or ethinyl estradiol $(20-50 \mu \mathrm{g} /$ day) are used in combination with various synthetic progestins, such as norethindrone, norethindrone acetate, norgestrel, ethinodiol diacetate or norethynodrel $(0.3-100 \mathrm{mg} /$ day $)$. The hormones are physical and/or sexual violence at some time in their lives. In some regions, women who experience violence are one and a half times more likely to become infected with HIV (UNAIDS, 2017).

HIV infection in India is not only confined to women with highrisk behavior but has also reached the low-risk population. Women are primarily at risk of HIV acquisition through sexual contact with their spouses practicing high-risk behavior or through sex work [5]. Hence, a desperate need exists to provide people with new, easy to use, safe and affordable methods of protection that will allow women to take the necessary measures themselves without having to negotiate with their partners [4]. 


\section{Risks in hormonal control of fertility}

The reason why some women may be reluctant to take combination oral contraceptives (COCs) consistently and correctly is a fear of possible adverse effects.

\section{Cardiovascular disease}

Historically, combination oral contraceptives have been associated with increased risks for myocardial infarction and stroke. Overall, oral contraceptives were found to multiply the effects of age and other risk factors for MI and stroke, rather than just add to them. Because cigarette smoking is far more prevalent among women of reproductive age than any of these other risk factors, it becomes by far the most important factor. Whereas early epidemiological studies of high-dose oral contraceptives found significantly increased risks of developing cardiovascular disease among users of combination oral contraceptives. Use of oral contraceptives by healthy women who do not smoke does not appear to be associated with an increased risk of either myocardial infarction or stroke.

Hypertension: As with the increased risks for MI and stroke, older formulations of combination oral contraceptives have been associated with significant elevations of blood pressure as well. The risk of hypertension appears to be much lower when estrogen and progestin doses are lowered. The mechanism for contraceptiveinduced changes in blood pressure is still unclear, with alterations in plasma angiotensinogen and increases in sodium and water retention being noted. Although these are primarily estrogenic effects, progestins may have a synergistic effect, as significant elevations in blood pressure have only been apparent in the combination products and not with either hormone alone.

\section{Thrombosis}

As doses of estrogenic were lowered to less than $50 \mu \mathrm{g}$, a marked drop in the incidence of fatal and nonfatal pulmonary embolism was noted, thus implying an estrogen dose-related effect. As with the other concerns for myocardial infarction, stroke, and hypertension, patient selection remains the most important method of reducing the incidence of these adverse effects. Women who are already at high risk for cardiovascular problems (hypertension, smoking and older than 35 years, or diabetes with vascular complications) or have already had a cardiovascular or thromboembolic event should not use combination oral contraceptives.

\section{Hepatomas}

It may occur in women taking oral contraceptive, the most common of which are focal nodular hyperplasia and liver cell adenomas. Hepatocellular cancer was also felt to be associated with combination oral contraceptives use. Here it is clear that estrogen and progesterone play a crucial role in anti-fertility activity but not without the serious side effects [3].

\section{Intrauterine System}

The FDA approved the use of an intrauterine system (Mirena ${ }^{\circledR}$ ) that releases $20 \mathrm{mcg}$ of levonorgestrel per day and provides effective contraception for at least five years. This intrauterine system has been shown to be as effective as copper-containing intrauterine devices. Pregnancy rates are comparable with those occurring with surgical sterilization [6]. Although copper-containing IUDs can increase bleeding and dysmenorrhea, the levonorgestrel system lessens these symptoms [7]. The typical bleeding profile with the new intrauterine system is irregular bleeding or spotting for the first six months of use, followed by very light menses, with 20 percent of women having amenorrhea at one year of use. The amenorrhea results from the local action of levonorgestrel, which creates an atrophic endometrium. Because estradiol levels are maintained, osteopenia is not associated with this contraceptive method.

Because of the safety profile of the new intrauterine system and the high rates of oligomenorrhea and amenorrhea, the system currently is being evaluated for use in conditions such as dysfunctional uterine bleeding [8]. Only minimal side effects have been found with the intrauterine system. As with coppercontaining IUDs, there is a risk of expulsion and ectopic pregnancy. Side effects unique to the levonorgestrel system have been related to the hormonal component and include a slight increase in the rates of headaches and acne [7].

\section{Female barrier methods}

Female barrier methods are contraceptives that a woman places in her vagina before sex to prevent pregnancy. Mechanical barrier methods include devices such as the diaphragm, the cervical cap, and the female condom. The contraceptive sponge is both a mechanical and chemical barrier. In the past decade, this method has been updated and reintroduced in some countries. The diaphragm is a latex device that covers the cervix and part of the vaginal wall and is held in place by a flexible rim. The cervical cap is a smaller rubber device that fits snugly around the cervix. (Since the cap is not widely available, information presented below is focused primarily on the diaphragm, unless otherwise noted).

The female condom is a sheath made of thin, transparent, soft plastic that a woman inserts in her vagina before sex. It has two rings: a flexible removable ring at the closed end to aid with insertion, and a larger flexible ring that stays outside the vagina at the open end to help protect the external genitalia. Barrier methods are best suited for a woman who finds using a method near or at the time of intercourse acceptable, can learn the insertion technique, and has sufficient privacy for insertion and removal. In addition, women who use the diaphragm and cap must be able to care for and store the device. The methods can be very effective when used correctly and consistently with each intercourse. Typically, however, accidental pregnancy rates are high compared to many other methods. Women for whom an accidental pregnancy would present a serious health concern should use a more effective method. Barriers can provide important protection from sexually transmitted infections (STIs) and can be used even if a partner refuses to use condoms. Clients at risk for STIs could be counseled to use dual methods: a barrier method for STI protection and a second, more effective method for pregnancy prevention. Although significant challenges remain before safe and reliable microbicidal products will become readily available, some researchers have 
begun to reevaluate the protective nature of cervical barrier devices in protecting against bacterial and viral STIs. Key characteristics of mechanical barrier methods are highlighted below.

\section{Characteristics of mechanical female barrier methods}

A. Age limitations: No restrictions on age.

B. Parity limitations: No restrictions on use for nulliparous or parous women although parous women may experience higher rates of pregnancy with the diaphragm and cap.

C. Mode of action: Creates a physical barrier to block passage of sperm into the uterus and fallopian tubes; diaphragm and cervical cap effectiveness is increased by use of spermicide.

D. Effect on STI risk: Diaphragm and cervical cap are somewhat protective against that attack the cervix; the female condom offers significant protection for all STIs.

\section{E. Drug interaction: None.}

F. Duration of use: Used near or at the time of intercourse. The diaphragm and cap must be left in place for at least six hours after intercourse. Appropriate for both short-term and long-term use. Women can use barrier contraceptives throughout their reproductive years.

G. Return to fertility: Immediately upon discontinuation [9].

\section{Limitations of barrier contraceptives available in market}

Barrier contraceptives like diaphragm, cervical cap and vaginal sponge increases the pelvic pressure and causes the vaginal irritation, allergy and vaginal discharge if left in too long. Besides this female condom are aesthetically unappealing and for some women, it is awkward to use [10]. At present, such over the counter dual function microbicides include the neutral surfactants isononyl-phenyl-polyoxymethylene-(9)-ether or nonoxynol-9 $(\mathrm{N}$ 9), p-menthanyl-phenyl-polyoxyethylene-(8,8)-ether or menfegol, and isooctyl-phenyl-polyoxyethylene-(9)-ether or octoxynol-9 (09). N-9 is the most commonly used spermicidal contraceptive in UK and USA. Worldwide, the cationic surfactant benzalkonium chloride and the anionic detergent sodium docusate (dioctyl sodium sulphosuccinate) are also used as vaginal spermicides. N-9, sodium oxychloride, and benzalkonium chloride have been used as creams, gels, foams, suppositories, ovules, sponges, or film. The spermicidal and microbicidal activities of these surfactants are associated with their structural affinity to the membrane lipids. Therefore, the major drawback of using N-9 or other currently used surfactants is their detergent type effect on epithelial cells and normal vaginal flora. N-9 displays antiviral/antibacterial and spermicidal activities only at cytotoxic doses. Frequent use of N-9 as a vaginal contraceptive/ microbicide has been associated with an increased risk of vaginal or cervical infection, irritation, or ulceration. Detergent-type spermicides alter vaginal bacteria or flora and lead to an increased risk of opportunistic infections. Chemical irritation that disrupts the vaginal mucosa can enhance the risk of vaginal transmission of STDs including HIV-1, the causative agent of AIDS, by mucosal erosion and local inflammation. Therefore, vaginal spermicidal microbicides lacking detergent-type membrane toxicity may offer a significant clinical advantage over the currently available detergenttype spermicides. Because vaginal microbicides would likely be used repeatedly over decades, an ideal spermicidal microbicide should have an established safety record and lack genital epithelial toxicity. Moreover, it should be inexpensive, be produced from commonly available resources, and should have a broad specificity for solubilizing the drugs for prevention of sexual transmission of several STDs including HIV-1 [11]. Here it is clear that estrogen and progesterone play a crucial role in anti-fertility activity but not without the serious side effects and barrier methods available in market also have their own limitations [3]. So, the present study aims at providing novel contraceptive options that should be simple, safe, reversible, cost-effective and, overall, that would be acceptable to the majority of the world population irrespective of culture, religion and race [1].

\section{Herbal Options for Contraception}

The World Health Organization estimates that approximately 80percent of the World's population relies primarily on traditional medicines as sources for their primary health care. Natural products, including plants, animals and minerals have been the basis for treatment of human diseases. History of medicine dates back practically to the existence of human civilization. The current accepted modern medicine or allopathy has gradually developed for years by scientific and observational efforts. However, the basis of its development remains rooted in traditional medicine and therapies. The history of medicine includes many ludicrous therapies. Nevertheless, ancient wisdom has been the basis of modern medicine and will remain as one important source of future medicine and therapeutics. The future of natural products drug discovery will be more holistic, personalized and involve wise use of ancient and modern therapeutic skills in a complementary manner so that maximum benefits can be accrued to the patients and the community [12].

In recent years the use of herbal medicines for the therapy has increased tremendously. Hence there is a greater concern about the safety, efficacy and quality of herbal medicines. For many years herbal medicines have been used without the prescription. The plants used for various diseases have lost their therapeutic value because of the poor-quality control, contaminations or allopathic adulteration. The concept that herbal drugs are safe and free from toxic effects, are no more. Plants do contain hundreds of compounds; some of them are very toxic. The export of medicinal plant suffers mainly because of the ignorance related to regulations, demand dynamics and standardization [13]. Plants have been used worldwide for treatment of various human ailments since antiquity. Their use is still quite prevalent in developing countries in the form of traditional/folklore system of medicine. Intensive chemical and pharmacological studies on traditional/folklore medicinal plants during the last 5 decades have led to the validation of traditional claims in many cases and facilitated identification of their active principles. The active principles have provided leads in the development of several lifesaving drugs, which are in clinical use today. Many these plants are used for birth control in different countries. The status of scientific validations of their antifertility potential and identification of active principles during the last 
3 decades shows that approximately 318 different plants are in traditional/folkloric use worldwide, of which 227 plants are of Indian origin. Out of these, 74 plants have been screened for their anti-fertility potential, 48 of them have been found to be effective and active principles of about 15 plants have been identified till 2004. In modern system of medicine, about $25 \%$ of prescriptions contain active principle(s) derived from plants. Plant kingdom, therefore, holds a great promise for the discovery of new and effective anti-fertility agents. There are approximately 250,000 species of plants growing on earth and therefore, some criteria are to be laid down for selecting the plants that have anti-fertility potential. Three options are available, i.e.

A. investigation of plants that have folkloric/traditional reputation as contraceptives,

B. evaluation of plants that are known to contain constituents, which theoretically affect the female cycle to produce anti-fertility effects e.g. estrogenic sterols, isoflavones, and coumastranes or that have potential to contract uterus.

C. Random collection of plants for mass screening for fertility regulation [14].

Many of these plants cannot be recommended for practical use due to a lack of complete pharmacological profile. Further research is needed to find reliable contraceptives derived from plants that do not produce harmful side effects. Such contraceptives would be especially useful in those cases where hormonal contraceptive agents are contraindicated [15]. Following is the list of plants available for anti-fertility activity with their parts used and somewhere mechanism of action to understand this activity.

\section{Alangium salviifolium}

The family Alangiaceae consists of twenty-two species out of which A. salviifolium (Linn.f) Wang is mainly used as medicine in India, China and Philippines. Different parts of this plant are reported to possess acrid, astringent, emollient, anthelmintic, diuretic and purgative properties. It is also used externally in acute case of rheumatism, leprosy and inflammation. Applied externally and internally in case of rabid dog bite. Root bark is an antidote for several poisons. Fruits are sweet, cooling and purgative and used as a poultice for treating burning sensation and hemorrhage period. Daily administration of petroleum ether, ethyl acetate, chloroform, methanol or aqueous extracts of A. salvifolium at a dose of $100 \mathrm{mg} /$ $\mathrm{kg}$ body weight for eight days starting from the first day of pregnancy showed significant abortifacient activity in comparison to vehicle treated group. Interestingly, except petroleum ether and ethyl acetate extracts, all the extracts showed no anti-implantation activity. Eight days of drug treatment lead to resorption of fertilized ovum as noticed by red spots in the horns of uterus. Among the extracts, chloroform extract was found to be least effective followed by petroleum ether extract. Methanol extract showed total resorption sites in two animals. Aqueous and ethyl acetate extracts have also shown good activity. These results indicate that A. salviifolium (Linn.f) Wang produced mainly abortifacient activity and less anti implantation activity. It indicates that the herbal drugs may have anti-progesterone effect [16].

\section{Aloe vera (A. barbadensis)}

Lyophilized A. barbadensis at concentrations of $7.5 \%$ and $10 \%$ proved to be spermicidal due to the multiple microelements (boron, barium, calcium, chromium, copper, iron, potassium, magnesium, manganese, phosphorus and zinc) which were toxic to the tail of spermatozoa causing instant immobilization. These results suggest the possibility of using lyophilized A. barbadendis as a new, effective and safe vaginal contraceptive [17].

\section{Aristolochia tagala}

Aristolochia a large genus of shrubs, rhizomatous perennial herbs often twining, is distributed in tropical and termerate regions of the world. A. tagala is a perennial herb highly prevalent in Himalayas, Bihar, Assam and southwards in forest cleanings. The root of the plant is reported to contain aristolochic acid, which possesses tumor-inhibiting activity and has been used in the treatment of cancer, snakebite and helminthiasis [18]. Preliminary phytochemical studies revealed that the ethanolic extract showed the presence of alkaloids, saponins, flavonoid glycoside, steroids and phenolic compound. The ethanol extract of A. tagala showed significant reduction in the number of corpora lutea and increase in the number of resorptions in comparison to the control [19].

\section{Biophytum sanctivum}

Different extracts of B. sanctivum were tested for their antifertility activity. Ethyl acetate and n-butanol extracts significantly inhibited pregnancy in $4 / 6$ rats with mean number of implants $3.0 \pm 1.92(\mathrm{P} \leq 0.05)$. It is also understood that the chloroform and the ethanol extract significantly inhibited pregnancy in 5/6 rats with a mean number of implants $2.0 \pm 1.23(\mathrm{P} \leq 0.05)$ and $6 / 6$ rats with mean number of implants $0.00 \pm 0.00(\mathrm{P} \leq 0.05)$, respectively [20].

\section{Calotropis procera}

$90 \%$ ethanolic extract and aqueous extract of roots of $C$. procera produced temporary and reversible modification on estrous cycle on female Wister rats. It was characterized by absence of estrous phase whereas metestrus phases and diestrus stage were prolonged. Therefore, extracts provoked inhibition of ovulation with consequent reduction of cyclicity [21]. Ethanolic extract of roots shows $100 \%$ anti-implantation activity at the dose of $250 \mathrm{mg} /$ $\mathrm{kg}$ [22].

\section{Cardiospermum helicacabum}

Ethanolic extract of whole plant was given orally for day 1 to 7 of pregnancy showed significant decrease in the implantation sites. Animals treated with $500 \mathrm{mg} / \mathrm{kg}$ body weight showed $60 \%$ inhibition of implantation sites. After confirming the antiimplantation activity of ethanol extract, the extract was subjected to estrogenic/anti-estrogenic studies in immature ovariectomized albino rats. The increase in uterine weight was observed [23].

\section{Carica papaya}

Structural changes in the testis and epididymis of rats on treatment with the benzene chromatographic fraction of the chloroform extract of the seeds of $C$. papaya were studied. 
Administration of this fraction showed a total inhibition of sperm motility, reduced sperm count and infertility. It was concluded that the inhibition of sperm motility by the drug could be due to other epididymal factors rather than the sub cellular characteristics of the testis and epididymis [24]. Udoh et al. [25] has reported the activity of the alkaloid extract of $C$. papaya seeds on male reproductive physiology in rats. Each male rat was treated with $C$. papaya seed extract daily for three days for fecundity study, semen analysis and testis histopathology respectively. The results showed that the oral administration of $C$. papaya seed extract prevented ovum degeneration and induced testicular cell lesion. These observations led to the conclusion that the $C$. papaya seed extract oral administration could induce reversible male infertility [25].

\section{Cassia fistula}

Oral administration of aqueous extract of seeds of $C$. fistula to mated female rats from day 1-5 of pregnancy, prevented pregnancy. $100 \%$ pregnancy inhibition was noted at $500 \mathrm{mg} / \mathrm{kg}$ body weight [26].

\section{Curcuma longa}

Petroleum ether and aqueous extracts of turmeric rhizomes show $100 \%$ anti-fertility effect in rats when fed orally [27]. Implantation is completely inhibited by these extracts [28]. Curcumin inhibits 5a-reductase, which converts testosterone to 5a-dihydrotestosterone, thereby inhibiting the growth of flank organs in hamster [29]. Curcumin also inhibits human sperm motility and has the potential for the development of a novel intra vaginal contraceptive [30].

\section{Cuscuta reflexa}

Methanolic extract of $C$. reflexa stem had shown to significantly increased the carbonic anhydrase activity in the uterus of mice. This is associated with elevated level of progesterone, which is supporting the anti-fertility effect of the plant [31].

\section{Cyclea burmanni}

The petroleum ether and chloroform extracts of the roots of C. burmanni had found to possess significant anti-fertility effect in rats. Both these extracts exhibited partial and complete resorption of implants at various doses. In estrogenic activity study, both the extracts increased uterine weight and caused opening and cornification of vagina in immature rats [32].

\section{Eugenia jambolana}

Flowers of E. jambolana significantly decreased the fertilizing capacity of the male albino rats without any significant change in body or reproductive organ weight. It causes significant reduction in conversion of spermatogenesis at the early stages of meiosis leading to decrease in sperm count without any abnormality to spermatogenic cells, Leydig interstitial cells and Sertoli cells [33].

\section{Guaiacum officinale}

The hot aqueous extract of aerial parts caused abortion in the second and third trimesters only. At a dose of $480.75 \mathrm{mg} / \mathrm{kg}$, the extract did not reduce the litter size in mice when given during the first trimester of pregnancy [34].

\section{Jatropha curcus}

Fruits when fed to the female rats at a dose of $3.3 \%$ of the diet exhibited $100 \%$ effect. Seeds, when fed to female rats at a dose of $3.3 \%$ of the diet exhibited $100 \%$ effect [35]. Fetal resorption was observed with methanol, petroleum ether and dichloromethane extracts of fruits of $J$. curcus indicating the abortifacient property [36].

\section{Ocimum sanctum}

Treatment of albino rats with a benzene extract of $O$. sanctum leaves for 48 days decreased total sperm count, sperm motility, and forward velocity. The percentage of abnormal sperm increased in caudal epididymal fluid and the fructose content decreased in the caudal plasma of the epididymis and the seminal vesicles [37]. Histological and biochemical studies on mice fed with leaves showed evidence of mild impairment of spermatogenesis with significant reduction of seminal ph. There was also a decrease in the reducing substance, acid and alkaline phosphatases and mucoproteins. Treated male mice failed to fertilize females of proven fertility [38]. Benzene extract of the leaves showed anti- fertility effect in $80 \%$ rats whereas the petroleum ether extract showed the effect in only $60 \%$ animals. The extract did not reveal an abortifacient activity [39]. O. sanctum leaves have been reported to show abortifacient and anti-fertility activity. The aqueous extract also showed antiimplantation action [40].

\section{Pergularia daemia}

Oral administration of the ethanolic extract of $P$. daemia was found to terminate pregnancy in the pre-implantation stage in mice. But when the dose was reduced, it showed that the extract was able to prevent implantation or cause resorption depending upon the dose. To identify the bioactive fractions, the steroidal fraction was separated from the ethanolic extract and was tested for anti-fertility activity in mice. The fraction also exhibited anti-fertility activity in mice at pre-implantation stage. The possible cause of termination of pregnancy upon oral administration of the ethanol extract and its steroidal fraction from day 1 to day 9 of pregnancy might be due to anti zygotic, anti-blastocyte as well as anti-estrogenic property. The ethanolic extract also showed late abortifacient activity in the mice. The mice aborted all the fetuses within 48 hours of drug treatment. The present investigation clearly demonstrates that the ethanol extract and its steroidal fraction are able to prevent fertilization in the female mice [41].

\section{Stevia rebaudiana}

Aqueous extract of $S$. rebaudiana (Compositae) was fed orally to male Wistar albino rats for a period of 65 days. A control group was also maintained. The results revealed decrease in the epididymal sperm count, plasma testosterone concentration and decrease in organ body weight ratio of testis and cauda epididymis in the group fed with $5000 \mathrm{mg} / \mathrm{kg}$ body weight as compared to saline fed control group. This study revealed the anti-fertility effect of $S$. rebaudiana in adult male Wistar albino rats [42]. 


\section{Azadirachta indica}

Male albino rats, when administered $A$. indica leaf powder with or without testosterone orally and suitable controls were maintained, damaged seminiferous tubules and abundance of vacuoles of varying size were observed in A. indica treated rats. The germ cells showed overall decrease in cytoplasmic ground substance. Leydig cells exhibited characteristics of degeneration with condensed nuclei. Total count of spermatocytes, spermatids and Leydig cells were reduced. The cell and nuclear diameter of spermatogonia, spermatocytes, spermatids and Leydig cells were also reduced. From the result obtained, it can be observed that effects of Azadirachta indica on the testis are possibly due to gonadotrophic hormone deficiency, caused directly or indirectly [43]. Neem oil proved spermicidal against rhesus monkey and human spermatozoa in-vitro. In-vivo studies showed that intra vaginal application of neem oil prior to coitus can prevent pregnancy [44]. Anti-fertility effect of neem oil has also been studied and suggested to be a novel method of contraception [45]. Oral administration of aqueous extract of neem leaf also shows anti-fertility effect in mice [46]. Purified neem seed extract has also been demonstrated to abrogate pregnancy in both baboons and bonnet monkeys, when administered orally [19]. From the hexane extract of neem seed, an active fraction containing six components has been found to completely abrogate pregnancy in rodents with no apparent side effect [22].

It is well known fact that estrogenic substances inhibit pregnancy by suppressing the level of both follicular stimulating hormone (FSH) and luteinizing hormone ( $\mathrm{LH}$ ), which in turn prevent the implantation. Estrogen and progesterone are the hormones responsible for histological and functional modifications of female genital tract. The exogenous administration of physiological doses of estrogen, in sexual immature rats, stimulated history architecture of uterus. According to Laurence any compound possessing estrogenic activity may exhibit anti fertility activity, they act by suppressing gonadotrophin secretion, with consequent inhibition of ovulation. In immature female rats, hence the anti-implantation activity of these plants may be due to an imbalance in endogenous estrogen and progesterone levels. The loss of implantation caused by the extracts may be due to their anti-zygotic, blast cytotoxic or ant implantation activity as described by Hafez. Isoflavones along with coumarins (also flavonoids) and lignans belong to a class of substances known as non-steroidal phytoestrogens, they produce infertility in animals. According to Miksicek several commonly occurring flavonoids mimic the biological effects of $17 \alpha$-estradiol by virtue of their ability to bind to and activate the nuclear estrogen receptor.

The primary way in which a woman can prevent microbial infection and pregnancy through intercourse is with effective vaginal contraceptives. However, formulations generally available are not as effective as some other birth control methods. Therefore, spermicidal activity was also included in the present study to check that whether the plants can be used in the formulation of vaginal contraceptives. The results of the spermicidal activity tend to suggest that many plants showed spermicidal effect at lower concentration. It is interesting to note that use of herbal contraceptives generally did not lead to permanent sterility in rats, since discontinuation of the treatment allowed a prompt return to normal fertility [3].

\section{Withania somnifera}

The ethanolic extract of Withania somnifera had been evaluated, the minimum effective spermicidal concentrations of Withania somnifera stem extract by conducting "Sander-Cramer test" were found to be $10 \pm 0.06 \mathrm{mg} /$ million sperm. There were no morphological changes observed in the head, mid piece \& tail of sperm after the exposure of extract. In the in-vivo study, a dose dependent reduction in the epididymal sperm count and percentage motility were observed. These results showed that Withania somnifera extract has antifertility effect on male rat reproduction, sexual behavior and epididymal sperm concentration. Hence, ethanolic extract of Withania somnifera stem is a potent spermicide which completely immobilized the one million of rat sperm within 20s [47].

\section{Abrus precatorius, Ricinus communis, and Syzygium aromaticum}

The research was performed to investigate in vivo herbal contraceptive effects on the anatomy of the testis in male Swiss albino mice (Mus musculus) and to observe that whether the herbal extracts depart any harmful effects on the genitalia or not. Swiss albino mice at age of 30 days were used [48].

\section{Conclusion}

The present study proposes the novel, single step, cost effective contraceptive preparation and evaluation of its in-vitro spermicidal effect in human as well as rat spermatozoa and in-vivo contraceptive efficacy in female Wistar rat. Further work needs to be done on anti-microbial activity of NANE to support dual function of NANE as contraceptive as well effective in STIs such as syphilis, gonorrhea and HIV infection.

\section{References}

1. Kumara S, Biswasb S, Mandala D, Roy HN, Chakraborty S, et al. (2007) Chenopodium album seed extract: a potent sperm-immobilizing agent both in vitro and in vivo. Contraception 75(1): 71-78.

2. Garg S, Talwar GP, Upadhyay SN (1998) Immunocontraceptive activity guided fractionation and characterization of active constituents of neem (Azadirachta indica) seed extracts. J Ethnopharmacol 60(3): 235-246.

3. Qureshi AA, Sanghai DB, Padgilwar SS (2006) Herbal options for Contraception: A Review. Phcog Mag 2(8): 204-215.

4. Reddy KVR, Aranha C, Gupta SM, Yedery RD (2004) Evaluation of antimicrobial peptide nisin as a safe vaginal contraceptive agent in rabbits: in vitro and in vivo studies. Reproduction 128(1): 117-126.

5. Joshia SN, Katti U, Godbolea S, Bharucha K, Kumar KB, et al. (2005) Phase I safety study of praneem polyherbal vaginal tablet use among HIV-uninfected women in Pune, India. Trans R Soc Trop Med Hyg 99(10): 769774 .

6. Fortney JA, Feldblum PJ, Raymond EG (1999) Intrauterine devices. The optimal long-term contraceptive method? J Reprod Med 44(3): 269-274. 
7. French RS, Cowan FM, Mansour D, Higgins JP, Robinson A, et al. (2000) Levonorgestrel-releasing (20 micrograms/day) intrauterine systems (Mirena) compared with other methods of reversible contraceptives. BJOG 107(10): 1218-1225.

8. Hubacher D, Grimes DA (2002) Noncontraceptive health benefits of intrauterine devices: a systematic review. Obstet Gynecol Surv 57(2): 120128.

9. http://www.rho.org/html/cont-female_barriers.htm

10. Emily J, Herndon MD, Zieman MDM (2004) New contraceptive options. Am Fam Physician 69(4): 853-860.

11. Cruza OJD, Uckun FM (2001) Gel-microemulsions as vaginal spermicides and intravaginal drug delivery vehicles. Contraception 64(2): 113-123.

12. Patwardhan B, Vaidya A, Chorghade M (2004) Ayurvedic and natural product drug discovery. Curr Sci 86(6): 789-799.

13. Diwan PV (2005) Herbal research: Opportunities, threats, innovations and strategies. International conference on promotion and development of botanicals, Kolkata, India.

14. Maurya R, Srivastava S, Kulshreshta DK, Gupta CM (2004) Traditional remedies for fertility regulation. Curr Med Chem 11(11): 1431-1450.

15. Korkhov VV, Mats MN (1983) Contraceptive preparations of plant origin. Akush Ginekol Mosk 11: 8-10.

16. Murugan V, Shareef H, Sarma GVSR, Ramanathan M, Suresh B (2000) Anti-fertility activity of Alangium salvifolium. Indian J Pharmacol 32 388-389.

17. Jha NK, Pandey IK, Jha AK (2005) Aloe vera: Ghritkumari. Phytopharm 6(6): 3-22.

18. Anonymous (1985) The wealth of India: Raw Materials, Publication and Information Directorate CSIR, New Delhi, India.

19. Balaji S, Raj PP, Thomas J, Kumar KA (2004) Antifertility activity of ethanol extract of Aristalochia tagala leaf. Indian J Phrama Sci 66(6): 834836.

20. Johnson B, Kumar CD, Arunkanth KR, Giles D, Gopal M (2003) Antifertility activity of Biophytum sanctivum. Indian Drugs 40(9): 523-525.

21. Circosta C, Sonago R, Occhiuto F (2001) Effects of Calotropis precera on oestrous cycle and on oestrogenic functionality in rats. Farmaco 56(57): 373-378.

22. Jagdish VK, Rana AC (2002) Preliminary study of antifertility activity of Calotropis procera roots in female rats. Fitoterapia 73(2): 111-115.

23. Dhanwad R, Patil MG, Patil SB, Satyanarayan ND (2005) Antiimplantation activity of Cardiospermum helicacabum Linn. (Sapindaceae) in albino rats. Indian Drugs 42(11): 726-730.

24. Manivannan B, Mishra PK, Pathak N, Sriram S, Bhande SS, et al. (2004) Ultrastructural changes in the testis and epididymis of rats following treatment with the benzene chromatographic fraction of the chloroform extract of the seeds of Carica papaya, Phytother Res 18(4): 285-289.

25. Udoh FV, Udoh PB, Umoh EE (2005) Activity of alkaloid extract of Carica papaya seeds on reproductive in male Wistar rats. Pharm Biol 43(3): 563-567.

26. Yadav R, Jain GC (1999) Antifertility effects of aqueous extract of seeds of Cassia fistula in female rats. Adv Contracept 15(4): 293-301.

27. Garg SK (1974) Effect of Curcuma longa (rhizomes) on fertility in experimental animals. Planta Med 26(3): 225-227.

28. Garg SK, Mathur VS, Chaudhury RR (1978) Screening of Indian plants for antifertility activity. Indian J Exp Biol 16(10): 1077-1079.
29. Liao S, Lin L, Dang MT, Zhang H, Kao YH, et al. (2001) Growth suppression of hamster flank organs by topical application of catechins, alizarin, curcumin and myristoleic acid. Arch Dermatol Res 293(4): 200-205.

30. Rithaporn T, Monga M, Rajasekharan M (2003) Curcumin: a potential vaginal contraceptive. Contraception 68(3): 219-223.

31. Mazumdar UK, Gupta M, Pal DK, Bhattachara S (2003) Induction of carbonic anhydrase by Cuscuta reflexa stem and Corchorus olitorius seed in mice. Indian J Pharma Sci 65(4): 401-403.

32. Panda SK, Sahu SK, Dash GK (2003) Antifertility effect of Cyclea burmanni. Indian J Pharm Sci 65(3): 305-307.

33. Rajasekaran M, Bapana JS, Lakshmanan S, Ramachandran NAGS, Veliath AJ, et al. (1988) Antifertility effect in male rats of oleanolic acid, a triterpine from Eugenia jambolana flower. J Ethnopharmacol 24(1): 115-121.

34. Offiah NV, Ezenwaka CE (2003) Antifertility properties of the hot extract of Guaiacum officinale. Pharm Biol 41(6): 454-457.

35. Jha NK, Pandey IK, Jha AK (2006) Jatropha curcus: Jangli Erand. Phytopharm 7(3): 3-9.

36. Goonasetera MM, Unawwdana VK, Jayasena K, Mohammed SG, Balasubramanium S (1995) Pregnancy terminating effect of Jatropha curcus in rats. J Ethnopharmacol 47(3): 117-123.

37. Ahmed M, Ahmed RN, Aladakatti RH, Ghosesawar MG (2002) Reversible anti-fertility effect of benzene extract of Ocimum sanctum leaves on sperm parameters and fructose content in rats. Basic Clin Physiol Pharmacol 13(1): 51-59.

38. Kasinathan S, Ramakrishnan S, Basu SL (1972) Antifertility effect of Ocimum sanctum L. Indian J Exp Biol 10(1): 23-25.

39. Batta SK, Santhakumari G (1971) The anti-fertility effect of Ocimum sanctum and Hibiscus rosa sinensis. Indian J Med Res 59(5): 777-781.

40. Vora SB, Garg SK, Chaudhaury RR (1969) Antifertility screening of plants 3. Effect of six indigenous plants on early pregnancy in albino rats. Indian J Med Res 57(5): 893-899.

41. Sadik, Gafur MA, Shah M, Bhuiyan A, Alam AHMK, et al. (2001) Antifertility Activity of Pergularia daemia. Journal of Medical Sciences 1(1): 2224.

42. Prasad S, Jaykumar K, Honnegowda KN, Rao S (2005) Male reproductive toxicity of Stevia rebaudiana (bert.) in rats. Toxicol Int 12(1): 45-48.

43. Aladakatti RH, Ahmed RN (2006) Azadirachta indica A juss induced changes in spermatogenic pattern in albino rats. J Nat Remed 6(1): 6267.

44. Sinha KC, Riar SS, Tiwari RS, Dhawan AK, Bardhan J, et al. (1984) Neem oil as vaginal contraceptive. Indian J Med Res 79: 131-136.

45. Biswas K, Chattopadhyay I, Banerjee RK, Bandyopadhyay U (2002) Biological activities and medicinal properties of neem (Azadirachta indica). Current Sci 82(11): 1336-1345.

46. Despande VY, Mendulkar KN, Sadre NL (1980) Male antifertility activity of Azdirachta indica in mice. J Postgrad Med 26(3): 167-170.

47. Singh AR, Singh K, Shekhawat PS (2013) Spermicidal activity and antifertility activity of ethanolic extract of Withania somnifera in male albino rats. International Journal of Pharmaceutical Sciences Review and Research 21(2): 227-232.

48. Bhakta S, Abdul A, Das SK (2019) Herbal contraceptive effect of Abrus precatorius, Ricinus communis and Syzygium aromaticum on anatomy of the testis of male Swiss albino mice. J Adv Biotechnol Exp Ther 2(2): 36-43.

For possible submissions Click below: 